\title{
As pesquisas arqueológicas no Museu Paraense Emilio Goeldi (1870-1981)
}

\author{
Mario F. Simōes (*)
}

\begin{abstract}
Resumo
Desenvolvimento das pesquisas arqueológicas no Museu Paraense Emilio Goeldi, de sua fundação até os dias atuais, enfatizando a importância do Conselho Na. cional de Desenvolvimento Científico e Tecnológico (CNPq), a partir de 1955, na recuperação, reaparelhamiento e, sobretudo, dinamização do antigo setor de Arqueologia Amazônica, praticamente inativo desde início do século $\mathrm{XX}$. Focalizados os principais projetos de pesquisas empreendidos e em realização, seus objetivos e resultados alcançados, além de outras atividades no campo do ensino e da pesquisa arqueológica.
\end{abstract}

Quanto às pesquisas arqueológicas desenvolvidas pelo Museu Paraense Emilio Goeldi, apesar das contribuições pioneiras de Ferreira Penna, Emilio Goeldi e Lima Guedes, ou ainda mais recentemente, de Peter Hilbert, é a partir de 1962, alguns anos após a assinatura do convênio entre o Governo do Estado do Pará e o então Conselho Nacional de Pesquisas (CNPq), que a direção deste órgão federal passaria a dispensar melhor atenção e providenciar recursos para recuperar e dinamizar o antigo setor de Arqueologia do Museu Goeldi, praticamente inativo desde início do século. Se por um lado a construção e reforma de prédios para depósito das coleções, laboratórios e gabinetes de trabalho, aliadas à aquisição de móveis, equipamento e bibliografia, forneceram as bases físicas para seu funcionamento inicia!; por outro, a concessão de bolsas e maiores recursos para os trabalhos de campo completaram essa infra-estrutura mínima, facultando recrutar pessoal especializado e de apoio, organizar cursos e estágios e, conseqüentemente, reativar e imprimir maior rítmo às pesquisas e publicações.
Nesta comunicação é apresentada uma sinopse das contribuições prestadas pelo $\mathrm{Mu}$ seu Goeldi à Arqueologia Amazônica, de sua fundação até nossos dias, enfatizando a importância do Conselho Nacional de Desenvolvimento Científico e Tecnológico (CNPq) na recuperação e dinamização das pesquisas arqueológicas, em quase três décadas de sua atuação na Amazônia. Para melhor acompanhamento dividiu-se a história dessas pesquisas em dois períodos: o primeiro, desde sua fundação até a assinatura do Convênio Governo do Estado do Pará/Conselho Nacional de Pesquisas, em 1954; o segundo, desta data até os dias atuais (1981). São comentadas as principais contribuições e eventos ocorridos em cada período, acrescentando-se, porém, na apreciação do período atual, um relato sucinto sobre os projetos realizados e em execução, seus objetivos e resultados obtidos, além de informes relativos a outras atividades no âmbito do ensino e da pesquisa.

\section{PERÍODO PIONEIRO (1870 - 1954)}

Nos primeiros tempos de atividade do recém-fundado Museu Paraense, (') destacamse os trabalhos pioneiros de seu fundador Domingos Soares Ferreira Penna - em Marajó, Amapá, Tocantins e litoral do Pará, como naturalista-viajante do Museu Nacional do Rio de Janeiro. Nos campos de Marajó foi o primeiro a ali proceder escavações arqueológicas e, pelas observações então colhidas nos aterros dos Camutins (1870) e Pacoval (1871), a aventar a hipótese da origem artificial dos aterros marajoaras, posteriormente confirmada por outros pesquisadores. $\left({ }^{2}\right)$ Nos vários sítios prospec-

(*) - Museu Paraense Emílio Goeldi, Belém.

(1) - Inicialmente fundado como Sociedade Filomática (1866), em 1870 passou a denominar-se Museu Paraense, nome que permaneceu até 1901, quando foi substituído pelo de Museu Goeldi e, após 1931, novamente mudado para Museu Paraense Emílio Goeldi, denominação atual.

(2) - Foi motivado por tais informaçōes que Charles F Hartt, então chefe da Expedição Morgan, resolveu enviar seus assistentes Barnard (1871). Berkeley e Derby (1872) a Marajó, os quais, após examinarem os aterros em questăo, comprovaram as afirmaçōes de Ferreira Penna. 
cionados nos rios Mazagão e Maracá (1872), no atual Território do Amapá, coletou Ferreira Penrita regular número de urnas zoo e antropomorfas, até então inéditas; e, pela prospecção ao longo do baixo rio Tocantins e parte do litoral leste do Pará (1875), publicou a primeira notícia sobre a localização, destruição e conteúdo dos sambaquis do Pará (Ferreira Penna, 1876, 1877a e 1877b).

Contudo, é na administração de Emilio Goeldi (1894-1907) que o Museu Paraense, melhor instalado e estruturado, daria de fato início às pesquisas arqueológicas na Amazônia. Em 1895 é realizada a pesquisa de Goeldi nas cavernas funerárias do rio Cunani e, em 1896, a de Aureliano Lima Guedes nos sítios-cemitérios da ilha Pará, rios Mazagão, Maracá e Anauerapucu, ambas no atual Território Federal do Amapá. Dessas pesquisas resultaram as primeiras e melhores coleções hoje existentes de Cunani e Maracá, como também as primeiras contribuições à Arqueologia Amazônica publicadas pelo Museu Paraense (Guedes, 1897; Goeldi, 1900). $\left({ }^{3}\right)$

Após 1907, prolongando-se até meados do século, sofreu a Arqueologia no Museu Goeldi um longo período de inatividade e declínio, motivado por várias causas, entre as quais se destacam a partida de Goeldi para a Europa, a Guerra de 1914-18, a crise da borracha e, principalmente, a carência de recursos e pessoal especializado. No entanto, a presença do etnólogo Curt Nimuendaju, por duas vezes à frente da então Seção de Etnografia e Arqueologia, e a colaboração prestada pelo Museu às pesquisas de outras instituições, quer pelo estudo de suas coleções, quer ainda pelo apoio logístico oferecido, em parte compensaram o longo hiato nas pesquisas arqueológicas.

Nimuendaju, além de reorganizar as antigas coleções e acrescentar algumas peças por ele coletadias na área de Santarém e arredores, publicou um artigo no Boletim do Museu Paraense Emilio Goeldi, no qual são reunidas e condensadas todas as informações esparsas dos cronistas sobre os extintos índios Tapajó e, pela cerâmica destes, apresentadas possí- veis correlações com complexos arqueológicos centro-americanos (Nimuendaju, 1949) .

Da colaboração prestadas às pesquisas de outras instituições, merecem registro as de William C. Farabee (1914-18), Antonio Mordini (1926-28), Heloisa Alberto Torres (1930) e, em especial, as do casal Clifford Evans e Betty J. Meggers (1948-49). Foi na atual residência do Diretor do Museu Goedi que esses pesquisadores, na estação chuvosa de 1948-49, estabeleceram a primeira seqüência de desenvolvimento cultural da foz do Amazonas. mediante a análise de milhares de fragmentos de cerâmica escavados no Amapá e ilhas de Marajó, Mexiana e Caviana (Meggers \& Evans, 1957). Com essa nova abordagem de pesquisa arqueológica, até então inédita no Brasil, encerrarse-ia a etapa especulativo-descritiva dos primeiros anos da Arqueologia Amazônica.

Com a mesma abordagem metodológica, Peter P. Hilbert, etnólogo do Museu Goeldi e participante dos trabalhos de campo dos Evans em Marajó (1949), retomou as atividades arqueológicas do Museu, em recesso desde final do século XIX. Pela total falta de recursos na época, contou Hilbert com a colaboração de outras instituições, como o Instituto de Antropologia e Etnologia do Pará, procedendo escavações nos aterros de Marajó (1950-51), nas terras-pretas dos rios Nhamundá-Trombetas (1952) e nos sítios-cemitérios do baixo rio Cassiporé (1953).

Em 1954, com o convênio firmado entre o então Conselho Nacional de Pesquisas e o Governo do Estado do Pará, pelo qual assumia o Instituto Nacional de Pesquisas da Amazônia (INPA) a direção científica e administrativa do Museu Goeldi, encerrava-se o período pioneiro das pesquisas arqueológicas goeldianas.

\section{PERIOODO ATUAL (1955-1981)}

Com a aplicação maciça de recursos do CNPq foi sustada a decadência e inatividade do Museu. Seu escasso quadro técnico foi então fortalecido com a vinda de pesquisadores de alto nível, geralmente emprestados ou criun-

(3) - Ainda que trabalhos de outros especialistas do Museu Goeldi, principalmente geólogos, são de extrema utilidade para a Arqueologia as observaçōes sobre os sambaquis paraenses publicadas por Kraatz-Koschlau \& Huber (1900) e por Kratzer (1903). 
dos do Museu Nacional do Rio de Janeiro, iniclando-se a relevante tarefa de recuperar, reorganizar e reativar as pesquisas cientificas de há multo inativas.

Organizada a Divisăo de Antropologia, em 1955, recebeu o setor de Arqueologia e, obviamente. Peter Hilbert, apoio e recursos para prosseguimento de suas pesquisas. Desta data até 1961, quando regressou à Alemanha, realizou trabalhos de campo no médio rio Ama. zonas, foz do rio Negro e médio rio Japurá, dos quais resultou a identificação de várias fases e seqüências culturais de áreas até aquela época totalmente desconhecidas arqueologicamente. Dos resultados dessas pesquisas publicou diversos artigos no Brasil e no exterior, e, mais recentemente, uma monografia geral (Hilbert, 1952 - 1968).

A partir de 1962, em cumprimento à programação elaborada pelo INPA em 1955, empenhou-se a direção do Museu Goeldi ( $\left.{ }^{4}\right)$ na obtenção de recursos para equipar a recémcriada Divisão de Antropologia com um setor de Arqueologia compativel com os novos pa. drões vigentes no Museu Goeldi. Logo em meados de 1962 foi iniciada a construçäo de um prédio com $130 \mathrm{~m}^{2}$ para sua instalação, contendo um laboratório, duas saletas para técnicos e um amplo salão, este destinado a abrigar as coleçōes arqueológicas até então mal acondicionadas e dispersas pelos poröes da Rocinha. No ano seguinte, após confeccionados e montados os armários, estantes, gavetões e caixas para acondicionamento do material arqueológico existente, foi para ali transferido todo o acervo e inaugurado o prédio, o qual passou a denominar-se Pavilhão Frederico Barata em homenagem ao jornalista, artista e estudioso da Cultura Santarém, recém-falecido.

No início de 1969, considerando o desenvolvimento das pesquisas, o acervo acumulado e o crescimento de sua base física, passou a denominar-se Seção de Arqueologia, sendo designado para chefiá-la o Pesquisador-Chefe Mario Ferreira Simões que desde 1963 já vinha dirigindo o Setor. Em 1977, em decorrência da reorganização do Museu Goeldi, bem como para proporcionar maior liberdade de progra. maçăo e orçamentaçăo de recursos para suas atividades, fol desvinculada da tutela da Divlsão de Antropologia e elevada à categorla de Divisão, sob a mesma chefia anterior, e subordinada diretamente à Diretorla do Museu Goel. di. Posteriormente, face as normas de estrutura aprovadas pelo $\mathrm{CNPq}$, pelas quals eram transformadas em Departamentos as antigas Divisōes, passou a intitular-se Departamento de Arqueologia. Em 1980, porém, voltou a denominar-se Divisão de Arqueologia, compondo com a Divisão de Antropologia, o atual Depar. tamento de Ciências Humanas.

\section{AS LINHAS BASICAS DE PESQUISA}

Além das tarefas específicas de tombamento e curatoria das coleções arqueológicas do Museu Goeldi, tem a Divisão de Arqueolo. gia por objetivo o fiel cumprimento do Programa Básico de Pesquisas. da instituição, o qual, no tocante à Arqueologia Amazônica, comporta as seguintes linhas de pesquisa:

- Promover e intensificar as pesquisas na área da Amazônia Legal Brasileira, especialmente as de Arqueologia Pré-histórica, buscando obter uma perspectiva geral do processo de adaptação do Homem pré-colombiano a certas situações ambientais e ao uso de determinados recursos naturais, suas origens, $\mathrm{mi}$. grações, cronologia, desenvolvimento cultural e possiveis correlações com as demais áreas contíguas sul-americanas;

- Programar e realizar o salvamento de sítios arqueológicos (Arqueologia de Salvamento) ameaçados de destruição parcial ou total pelo surto de desenvolvimento urbanístico e tecnológico da área, como a construção de estradas, represas, indústrias etc.;

- Colaborar com a Secretaria do Patrimônio Histórico e Artístico Nacional (SPHAN) e outros órgãos congêneres, no tombamento, cadastro e fiscalização dos sítios arqueológicos, zelando pela fiel observância da Lei n? 3.924, de 24 de julho de 1971, que dispōe sobre a proteção dos monumentos arqueológicos e históricos brasileiros;

(4) - Cumpre aqui destacar todo o empenho e estímulo recebido dos diretores do Museu Goeldi - Eduardo Galvão (1961-62), Dalcy de Oliveira Albuquerque (1962-68) e Luiz Miguel Scaff (1969 ao presente) - na recuperação, reaparelhamento e dinamização da Arqueologia goeldiana. 
- Manter estreita colaboração com as áreas de pesquisa afins do Museu Goeldi e de outras instituições em programas de pesquisas de sua competência específica;

- Promover, dentro de suas possibilida. des, o preparo e aperfeiçoamento de pessoal especializado (arqueólogos e auxiliares técnicos) para o Museu e outros órgãos, mediante a programação e realização de cursos especiais e estágios;

- Empenhar-se na divulgação dos resultados de suas pesquisas e de outras atividades correlatas através de publicaçōes, exposições, congressos, palestras etc;

- Assessorar a Diretoria do Museu Goeldi nos assuntos atinentes a sua área de atuação.

\section{A BASE FISICA}

Com o desenvolvimento das pesquisas am. pliou-se o primitivo núcleo da Divisāo, abran- gendo atualmente 3 prédios próximos e parte do porão da Rocinha. O primeiro, o já mencionado Pavilhão Frederico Barata, com seus dois gabinetes para pesquisadores, um laboratório e o depósito para as coleções, do qual parte é ocupada por grande mesa para classificação de material e local para aulas, reuniōes e seminários. O segundo, obtido em 1975 após reforma e adaptação da antiga Seção de Entomologia, resultou uma área adicional de $100 \mathrm{~m}^{2}$, onde estão instalados um depósito para material estratigráfico e análise tipológica, um laboratório e sala para as coleções-tipo, um gabinete para pesquisador, além da Secretaria e Copa da $\mathrm{Di}$ visão. O terceiro, compreende uma área de $26 \mathrm{~m}^{2}$, dividida em duas saletas: uma reservada para alojar três técnicos, e outra destinada ao laboratório de restauração de material arqueológico. (Fig. 1 a 4).

Contudo, diante do volume de material coletado nos trabalhos de campo ultimamente

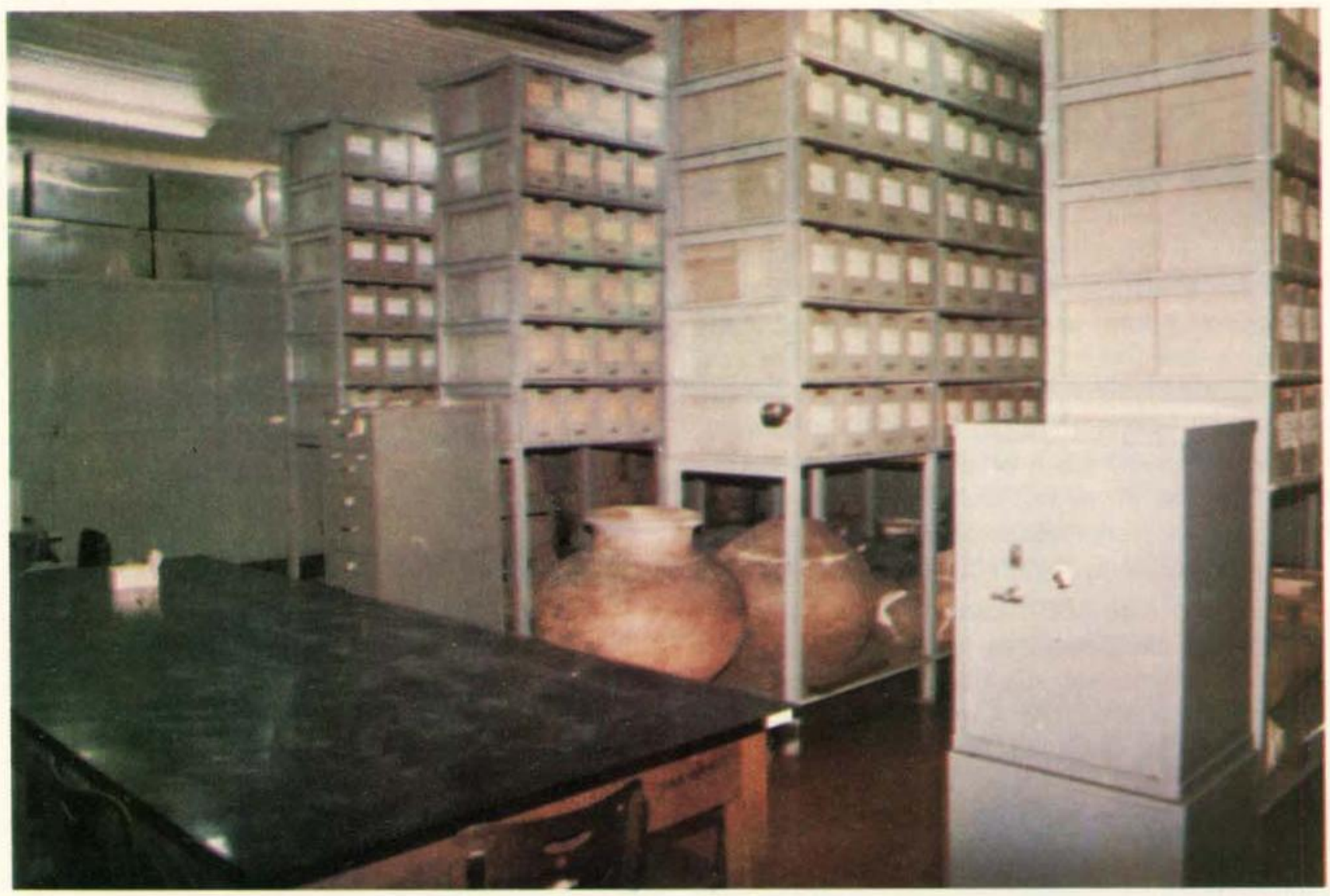

Fig. 1 - Interior do Pavilhāo Frederico Barata, com as estantes, armários, caixas e cofre para acondicionamento das coleçōes. (Prédio I). 


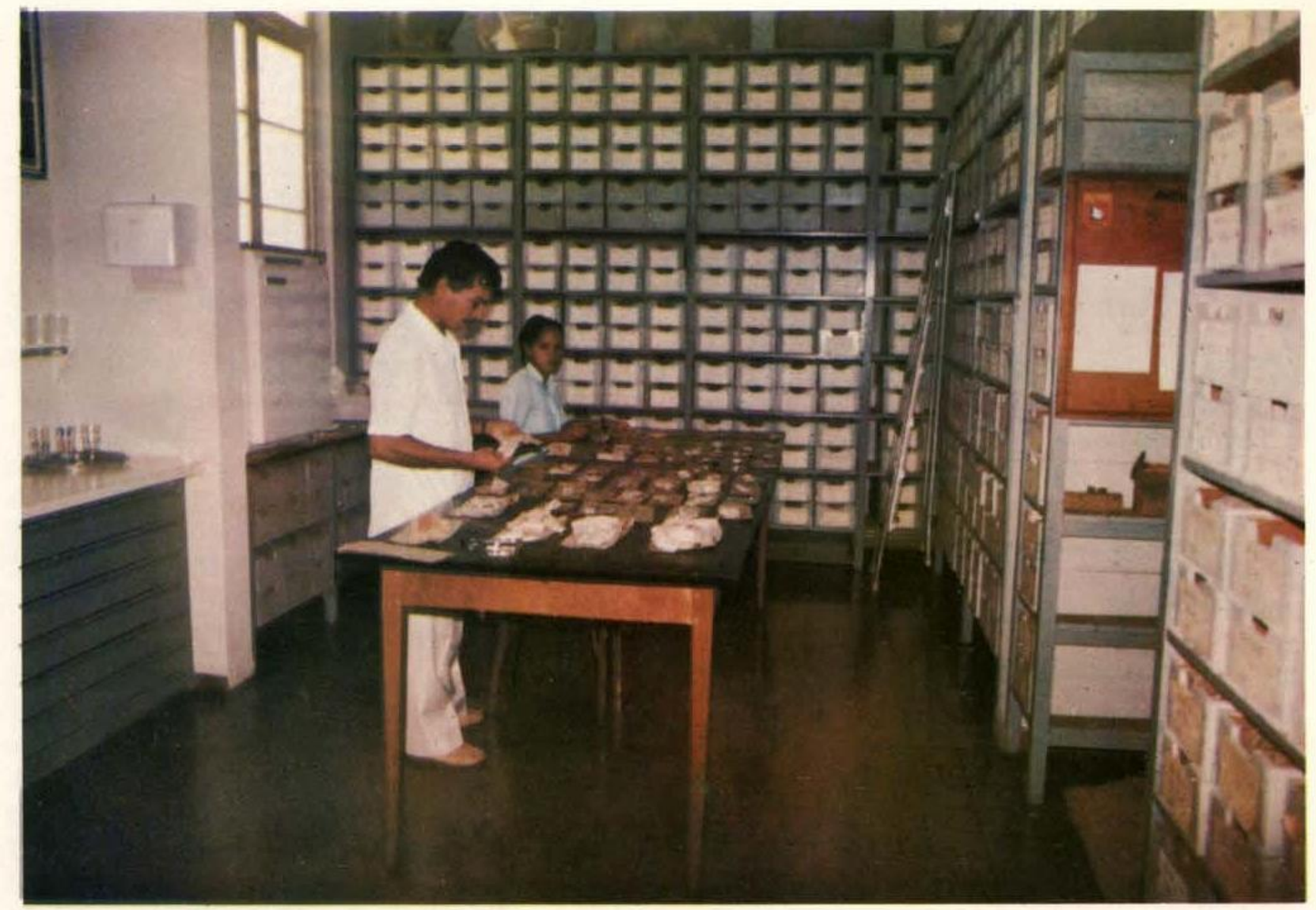

Fig. 2 - Vista do depósito para material estratigráfico e análise tipológica. (Prédio II).

realizados, voltou a faltar espaço para acondicionamento do material e, obviamente, de local para ser o mesmo manuseado e estudado. Mais uma vez foi a Divisão atendida pela Diretoria do Museu na cessão de $75 \mathrm{~m}^{2}$ no porão da Rocinha, na ocasião totalmente restaurada. Essa área, depois de equipada com estantes, bancadas, mesas para manuseio de material, caixas para as amostras estratigráficas, exaustores etc., serve no momento de depósito para - material estratigráfico dos projetos baixo Tocantins e baixo Uatumã-Jatapu, além de local para análise e estudo desse material.

Não obstante os acréscimos sucessivos. ressente-se ainda a Divisão de espaço e contigüidade. Os prédios são praticamente isola. dos, dificultando a comunicação, não havendo èspaço disponível para futuras admissões de técnicos ou mesmo de estagiários. No tocante ás depósitos de material arqueológico, a previsão é de 3 anos no máximo, caso seja man- tido o atual rítmo dos trabalhos de campo. Há, portanto, urgente necessidade em construir-se um prédio único, com área mínima de $700 \mathrm{~m}^{2}$, no atual terreno do Museu Goeldi ou alhures, para instalação definitiva da Divisão, caso se pretenda, como é propósito do $\mathrm{CNPq}$, manter a pesquisa arqueológica na Amazônia em um nível de qualidade conciliável com a conjuntura científica moderna.

\section{TREINAMENTO DE PESSOAL}

$$
\text { a - MESTRADO }
$$

A pós-graduação em Arqueologia vem sendo obtida através de o Curso de Mestrado em Antropologia Social (área de concentração em Arqueologia), mantido pela Universidade de São Paulo (USP), até o momento o único centro de pós-graduação em Arqueologia no Brasil. 
Duas Assistentes de Pesquisa, sob a orientação do Prof. Dr. Ulpiano B. de Meneses, já concluiram os respectivos créditos: Conceição de Maria G. Corrêa, já com seu Exame de Qualificação aprovado e em fase de preparo da dissertação; e Fernanda H. J. de Carvalho de Araujo Costa, concluinte em 1979 e com seu Memorial para o Exame de Qualificação pronto, aguardando ser examinado em março de 1981 .

\section{b - ESTÁGIO DE APERFEIÇOAMENTO}

Ministrado para as Assistentes de Pesquisa, mediante a coordenação e orientação do Pesquisador Mario F. Simões, tem por objetivo o preparo e aperfeiçoamento em Metodologia e Técnicas Arqueológicas, visando o futuro ingresso dos concluintes no Curso de Mestrado em Arqueologia da USP, considerando condição básica para aceitação no referido Curso ser profissional (de instituição de pesquisa), com trabalhos já realizados e em andamento. Consta o estágio de aulas, leituras e seminários sobre Teoria e Metodologia, Arqueologia Americana e Amazônica, bem como trabalho de campo intensivo e longo treinamento em laboratório (análise e classificação de material) .

\section{C - ESTÁGIO BÁSICO}

Destinado a iniciantes, geralmente Estagiários, comporta temas gerais teóricos sobre Arqueologia e, principalmente, uma grande ênfase nos trabalhos de laboratório, como manuseio, análise e classificação preliminar de material arqueológico, uso de binocular para determinar tipo de tempero, textura etc. da pasta, além da parte de fichamento bibliográfico e técnicas de Curatoria. De modo geral, este tipo de estágio é destinado a universitários dos cursos de História, Geografia e Ciências Sociais, fazendo os mesmos jus a bolsas de estudo patrocinadas pela SUDAM ou pelo CNPq.

\section{d - estágros espectais}

Além dos estágios regulares (Básico e Aperfeiçoamento), a Divisão vem concedendo estágios avulsos a pesquisadores e professores de outras instituições, quer para atualiza-

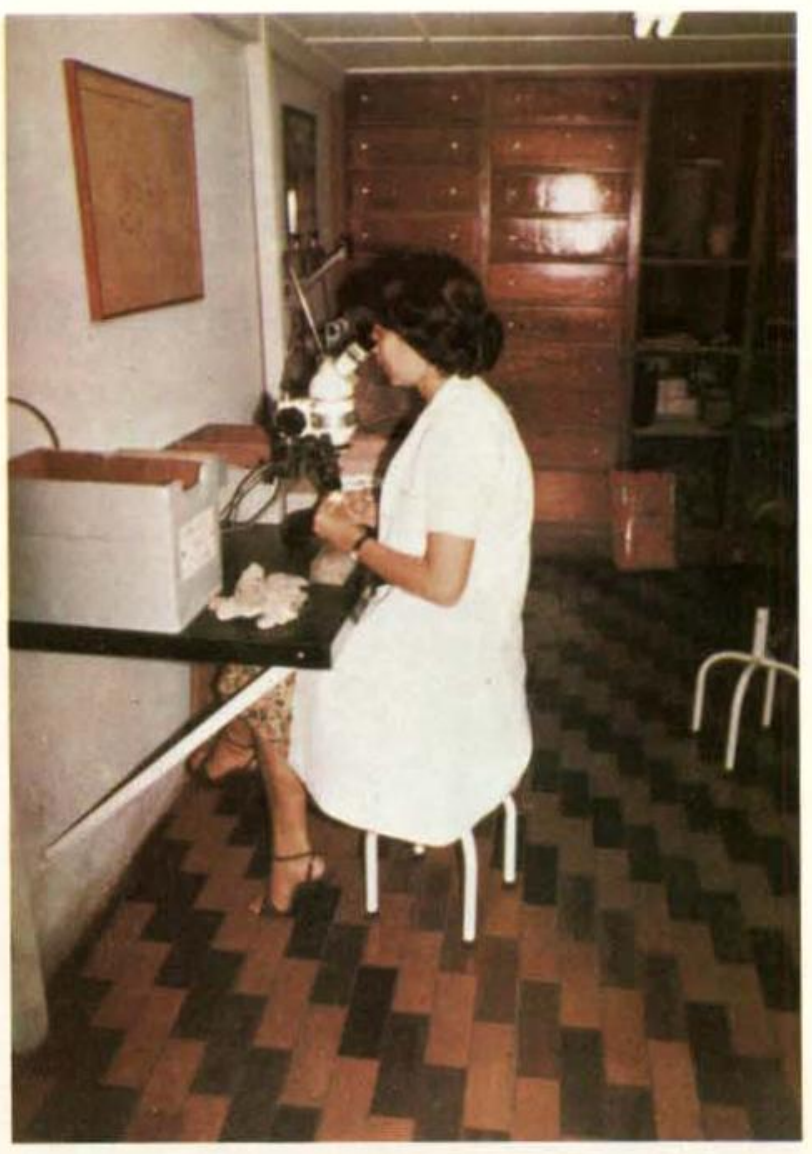

Fig. 3 - Laboratório para análise de material e deposito das coleções-tipo. (Prédio II).

ção em Arqueologia (Arqueologia Amazônica, Metodologia, Técnicas de laboratório etc.), quer também para estudos específicos das coleçōes, objetivando preparo de dissertaçōes para fins de pós-graduação.

\section{e - cursos}

No tocante aos cursos de Arqueologia ministrados pela Divisão, por sua complexidade. tempo absorvido, custo e dificuldades em conseguir professores de certas disciplinas, vêm sendo planejados intermitentemente, obedecendo nossas disponibilidades e urgência no preparo de pessoal especializado. Até o momento, foram programados e concluídos, com ótimos resultados, dois cursos, ambos em regime de tempo integral e em nível de pós-graduação.

O primeiro, em 1964-65, compreendia duas partes. A primeira, em 1964, de âmbito geral e introdutória a toda a então Divisăo de Antro- 
pologia (Curso Básico), objetivava a atualização e complementação em Ciências Antropológicas; a segunda, em 1965, denominada Curso de Aperfeiçoamento ou Especialização, tinha por finalidade a diversificação dos alunos nas três especialidades de Divisão - Arqueologia, Etnologia e Lingüística Indígena. Do curso de Arqueologia foram aproveitados dois alunos, um dos quais permanece até hoje no Museu.

O segundo - Curso de Arqueologia Brasileira - foi realizado no período de 1969-70, contando entre os alunos, além de pessoal local, com dois professores de outras instituiçōes - um da Universidade Federal de Minas Gerais e outro da Universidade Federal de Santa Catarina.

Em ambos os cursos, além das disciplinas básicas, como Teoria e Metodologia em Arqueo. logia, Antropologia Cultural e Etnografia do Brasil, Arqueologia Americana, Brasileira e Amazônica, foram ainda ministrados fundamentos e noções de Geologia e Petrografia, Topografia e Geomorfologia, Ecologia, Paleontologia, Malacologia e Sistemática. Como disciplinas accessórias, os alunos freqüentaram um curso intensivo de Fotografia e outro de Inglês. Dos trabalhos práticos, participaram os alunos de todas as operações de manipulação e tombamento de espécimes arqueológicos, fichamento bibliográfico, análise e classificação de material e trabalhos de campo.

\section{AS PESQUISAS ARQUEOLOGICAS}

Até final de 1980 foram programados e realizados 11 projetos de pesquisas, uns já concluídos e outros em prosseguimento ou em fase de conclusão. Dos projetos realizados ponderável quantidade de informaçōes vem-se acumulando sobre a origem, migrações, cronologia e desenvolvimento cultural de antigas populaçōes indígenas pré-históricas da Amazô. nia Brasileira, quer de áreas arqueologicamente desconhecidas, como alto Xingu, litoral do Salgado, lago de Silves, ilha de São Luís, baixo

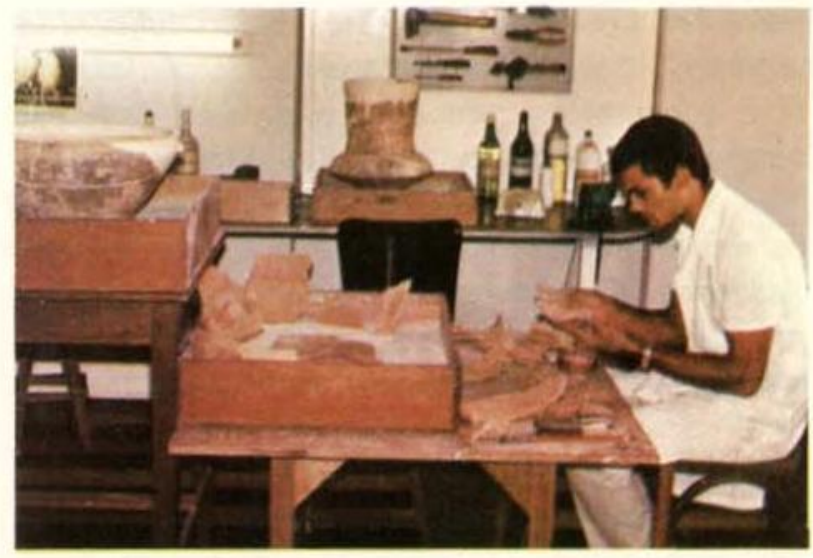

Fig. 4-Setor de restauração de material arqueológico. (Prédio III).

Tocantins, médio rio Negro, baixo Uatumã-Jatapu e médio rio Urubu, quer de outras, que, pela extensão geográfica, haviam sido parcialmente pesquisadas no passado, como ilha de Marajó e baixo rio Negro, ou ainda, apenas descrita, como o lago Cajari, na Baixada Maranhense. Destes projetos, cinco já foram objeto de trabalhos publicados - Marajó, alto rio Xingu, baixo rio Negro, litoral do Salgado e lago Cajari; $\left({ }^{5}\right)$ quatro estão em fase de análise e classificação do material coletado lago de Silves, ilha de São Luís, baixo rio Tocantins e médio rio Negro; e os dois últimos - baixo rio Uatumă-Jatapu (1979) e médio rio Urubu (1980), pela recência dos trabalhos de campo, encontram-se em fase de análise preliminar e lavagem, respectivamente.

1 - Projeto Marajó (1962-1965) - Iniciado em 1962, sob a responsabilidade de Mario F. Simões e Napoleão Figueiredo, com $\sigma$ patrocínio do Museu Goeldi e da Universidade Federal do Pará, o projeto estendeu-se até $1965 \mathrm{com}$ apoio financeiro do Museu Goeldi e IPHAN. Além do treinamento de alunos e estagiários. o projeto tinha por finalidade comprovar a seqüência local estabelecida por Meggers \& Evans (1957) para a parte central da ilha e obter amostras de carvão de fogueiras para fins de datação por $\mathrm{C}_{14}$. (Fig. $5 a$ ) .

Localizados e pesquisados 16 sítios arqueológicos inéditos (10 da fase Marajoara, 5 da

(5) - Cf. Corrêa \& Simōes, 1971: Figueiredo \& Simōes. 1963; Simōes, 1967a, 1967b, 1969, 1971, 1973, 1974 e 1981; Simões et al., 1977. 
fase Formiga e 1 das fases Ananatuba/Mangueiras). Dos dados obtidos estratigraficamente e a posterior comparação com os daqueles autores, importantes subsídios foram acrescidos à arqueologia da ilha de Marajó, dentre os quais as primeiras datações absolutas para as fases Ananatuba/Mangueiras e Marajoara, resultando, cronologicamente, na reformulação total da seqüência então estabelecida para a ilha de Marajó (Simões, 1967a). A datação de 980 a.C. obtida para a fase Ananatuba permitiu considerar esta fase como uma das mais antigas culturas ceramistas da Amázônia e incluí-la, temporalmente, no Formativo Americano (Simões, 1969). Para a fase Marajoara, as três datações conseguidas - A.D. 480,580 e 690 - facultaram situar a fase como introduzida na ilha de Marajó em A.D. 400 , estendendo-se até A.D. 1200 (Simões, 1973).

2 - Projeto Alto Xingu (1966) - Sob a responsabilidade de Mario F. Simões e patrocínio do Programa Nacional de Pesquisas Arqueológicas (PRONAPA), $\left({ }^{6}\right)$ teve como área de trabalho o Parque Nacional do Xingu (MT). O projeto objetivava verificar a presença de possiveis padrões culturais da faixa litorânea brasileira que, muito embora não se tenham difundido na Amazônia, poderiam ter penetrado na área alto xinguana, considerando a posição desta no limite meridional da Amazônia. (Fig. 5b).

Foram pesquisados 12 sítios-habitações no curso superior do Xingu e no baixo curso de alguns de seus tributários. Da análise e interpretação do material coletado foram identificadas duas fases arqueológicas distintas e relativamente recentes - Diauarum e Ipavu. A fase Diauarum faz-se representar por 7 sítios na mata ciliar do rio Xingu e seus afluentes Suiá-miçu e Manitsauá, enquanto a fase Ipavu por 5 sítios ao longo da lagoa Ipavu e pequenos afluentes do baixo rio Culuene. Ambas as fases pertenceram a grupos de horticultores de floresta tropical e, pelos traços diagnósticos da cerâmica, incluídas na tradição Incisa Pon. teada da Amazônia Brasileira, aliás, a primeira ocorrência dessa tradição até então registrada ao sul do rio Amazonas. A fase Diauarum está datada por $\mathrm{C}_{14}$ em A.D. 1100 a 1300 e a Ipavu de A.D. 1250 a 1400. (Simões, 1967b e 1973)

3 - Projeto Salgado (1968-1974) - Pesquisas sob a responsabilidade de Mario F. Simões e Conceição G. Corrêa, sob o patrocínio do Museu Goeldi e IPHAN. Inicialmente programado como Arqueologia de Salvamento para os sambaquis residuais do litoral paraense (área do Salgado), foi a seguir ampliado com a inclusão de outros sítios não-sambaquis (sítios abertos), considerando-se a possibilidade de seu correlacionamento cultural e cronológico com os sambaquis. O projeto tinha por objetivo estabelecer uma seqüência de desenvolvimento cultural da área litorânea do Pará, a partir de sua ocupação por grupos humanos adaptados aos recursos do mar e a posterior transição para horticultores de floresta tropical, como também, através de colaboração interdisciplinar, tentar reconstituir os padrões de subsistência, assentamento e cronologia desses antigos grupos do litoral paraense. (Fig. $5 c, d$ e e).

Localizados e pesquisados 62 sítios (43 sambaquis litorâneos, 16 sítios não-sambaquis e 3 sítios com gastrópodes fluviais) na orla costeira do leste paraense e já identificadas as fases Mina, Uruá, Tucumã e Areão. A fase Mina se faz representar pelos sambaquis litorâneos localizados, principalmente, entre as baías de Maracanã e Quatipuru. Material ergológico restrito a cerâmica rudimentar e artefatos de pedra, osso, concha e dente. Subsistência típica de coletores-pescadores litorâneos. Datações por $\mathrm{C}_{14}$ variam de 3.000 a 1.600 a.C., importando ser esta fase a mais antiga cultura ceramista do Brasil e uma das mais recuadas das Américas (Simões, 1973 e 1981). A fase Uruá, reconhecida em 3 sítios nas colinas do médio rio Quatipuru, apresentou nos refugos de ocupação grande quantidade de conchas de gastrópodes fluviais, conhecidos como

(6) - Programa de âmbito nacional mediante convênio entre o CNPq e a Smithsonian Institution, com a colaboração do então Instituto de Patrimônio Histórico e Artístico Nacional. Tinha por objetivo pesquisas extensivas nos diversos Estados e Territórios brasileiros, realizadas por 11 arqueólogos nacionais entre 1966 a 1970. (Cf. Simōes Ed., 1967, 1969a, 1969b, 1971 e 1974). 
"uruá" (Pomacea sp.). Cerâmica melhor elaborada, com artefatos líticos e adornos de conchas e dentes. Subsistência típica de coletores-pescadores-caçadores e antiguidade datada por $C_{\text {: }}$ em 1.700 a.C. (Simões, 1973). A fase Tucumã foi identificada em 4 sítios abertos localizados nas encostas de colinas, no médio rio Quatipuru. Ceràmica bem elaborada, com vários tipos decorados e artefatos líticos polidos. Subsistência também de coletorespescadores-caçadores e datação por termolumınescência variando de A.D. 228 a 750 . A fase Areão, localizada em 2 sítios na área de dunas da ilha de Marudá, apresenta uma cerâmica bem manufaturada, com formas maiores que nas demais fases, inclusive com grelhas ou assadores circulares. Subsistência do tipo de horticultores de floresta tropical e datação por termoluminescência acusando A.D. 1430 a 1580 (Corrêa \& Simões, 1971).

A fase Mina e uma outra do baixo Amazonas - fase Castália - pelos traços diagnósticos da cerâmica e outras evidências, permitirarn reconhecer a existência de uma tradição ceramista regional de ampla distribuição areal - tradição Mina - representada, até o momento, pelos sambaquis litorâneos do Pará (fase Mina), os sambaquis fluviais do baixo Amazonas (fase Castália), baixo Tocantins e baixo Xingu (fase Macapá), correlacionando-se ainda com os sambaquis litorâneos do Maranhão e os da fase Alaka, na faixa costeira da Guiana. (Simões, 1981).

\section{4 - Projeto Baixo rio Negro (1968-1969) -} Pesquisas de Mario F. Simões e Conceição G. Corrêa, sob o patrocínio do PRONAPA, nos arredores do baixo rio Negro (AM). O projeto tinha por objetivo verificar a possibilidade do rio Negro ter servido como rota de migração de povos e/ou idéias da região subandina para a Amazônia ou vice-versa, como também delimitar as áreas de ocorrência das principais tradições ceramistas da Amazônia e suas influências com relação ao médio rio Amazenas. (Fig. 5f)

Foram localizados e pesquisados 10 sítios. habitações ( 5 no baixo rio Negro, 2 no baixo rio .Apuaú, 2 nc médio rio Preto-da-Eva e 1 na iiha de Terra Nova), $\left({ }^{7}\right)$ identificadas 3 novas fases arqueológicas - Umari, Apuaú e Pajurá - e redefinidas 3 outras anteriormente descritas - Paredão, Guarita e Itacoatiara. A fase Umari, reconhecida em 2 sítios no médio Pretoda-Eva em associação com material da fase Guarita, apresentou forte semelhança com a cerâmica da fase Taruma, do alto Essequibo, na Guiana, atribuída aos indios Tarumá, emigrados do baixo rio Negro no século XIX. As fases Apuaú e Pajurá fazem-se representar associadas em 2 sítios no rio Apuaú. A primeira, pelas técnicas decorativas da cerâmica, foi incluída na tradição Policroma da Amazônia, enquanio a segunda, apesar de algumas técnicas incisas sugerirem paralelo com a fase Paredão, não se enquadrou em nenhuma das traaições amazônicas. Todas as fases são de grupos horticultores de floresta tropical com antiguidade datada por $\mathrm{C}_{14} \mathrm{em}$ : A.D. 390 a A.D. 750 para as fases Paredão/Guarita e A.D. 825 para a fase Apuaú.

Pela presença de material cerâmico semeIhante ao da fase Guarita em várias localidades da Amazônia Ocidental, compreendidas entre Santo Antônio do Içá (a oeste), foz do rio Uatumã (a leste), baixos cursos dos rios Madeira e Purus (ao sul) e médio rio Negro (ao norte), foi reconhecida e proposta a subtradição Guarita para representar dentro da tradição Policroma todas as manifestações locais e fases com traços diagnósticos da fasetipo Guarita. (Simões, 1974).

5 - Projeto lago de Silves (1970) - Pesquisas efetuadas na região do lago de Silves ou Saracá $(\mathrm{AM})$, sob a coordenação de Mario $\mathrm{F}$. Simões e a participação dos alunos do Curso de Arqueologia Brasileira, mediante financiamento do Museu Goeldi e a colaboração da Fundação de Amparo à Pesquisa do Estado de São Paulo (FAPESP). A pesquisa tinha por finalidade a complementação das pesquisas anteriormente realizadas em áreas contíguas, como as de Hilbert (foz do rio Negro, Itacoatiara e Manacapuru) e as de Simões (baixo rio Negro, rios Apuaú e Preto-da-Eva e ilha de Terra

( 7 ) - Em 1974, Mario F. Simōes, Ana Lúcia Machado e Eneida Ch. Malerbi localizaram e pesquisaram mais 11 sítios nos arredores do baixo rio Negro, na maior parte pertencentes às fases Paredão e Guarita. 

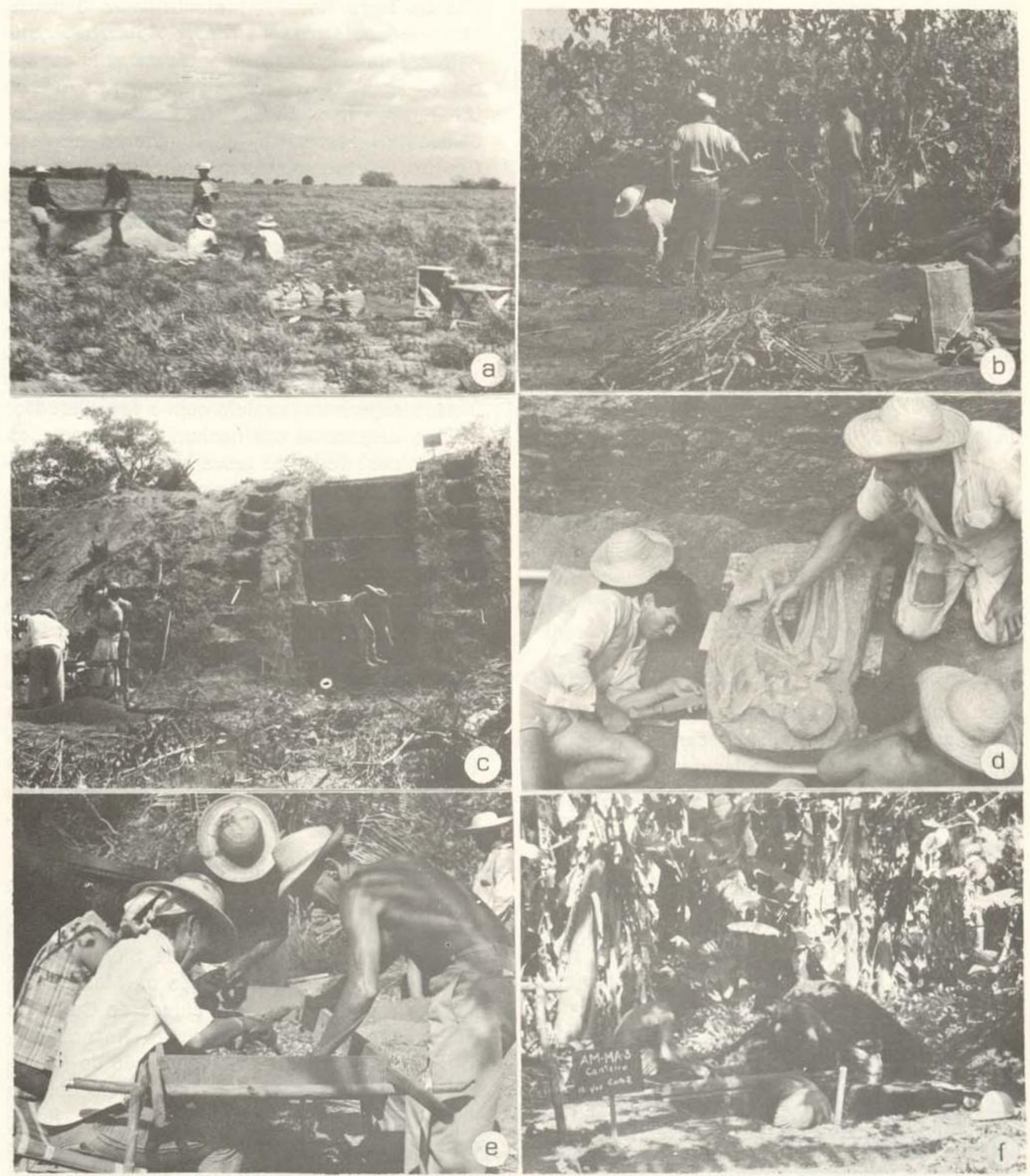

Fig. 5 - Trabalho de campo dos projetos: a - escavaçāo de um sítio da fase Formiga em área de campo, na ilha de Marajó; b - abertura de um corte-estratigráfico em Makahuku, no rio Tutuari, Alto Xingu; c - escavação da trincheira no sambaqui PA-SA-5: Porto da Mina, no Salgado; d - preparação e retirada do sepultamento n. 2 no sambaqui PA-SA-6: Ponta de Pedras, no Salgado; e - coleta de material peneirado no sambaqui PA-SA-30: Cocal, no Salgado; f - escavação do sítio AM-MA 3: Canteiro, na ilha de Terra Nova. nos arredores do baixo rio Negro. 

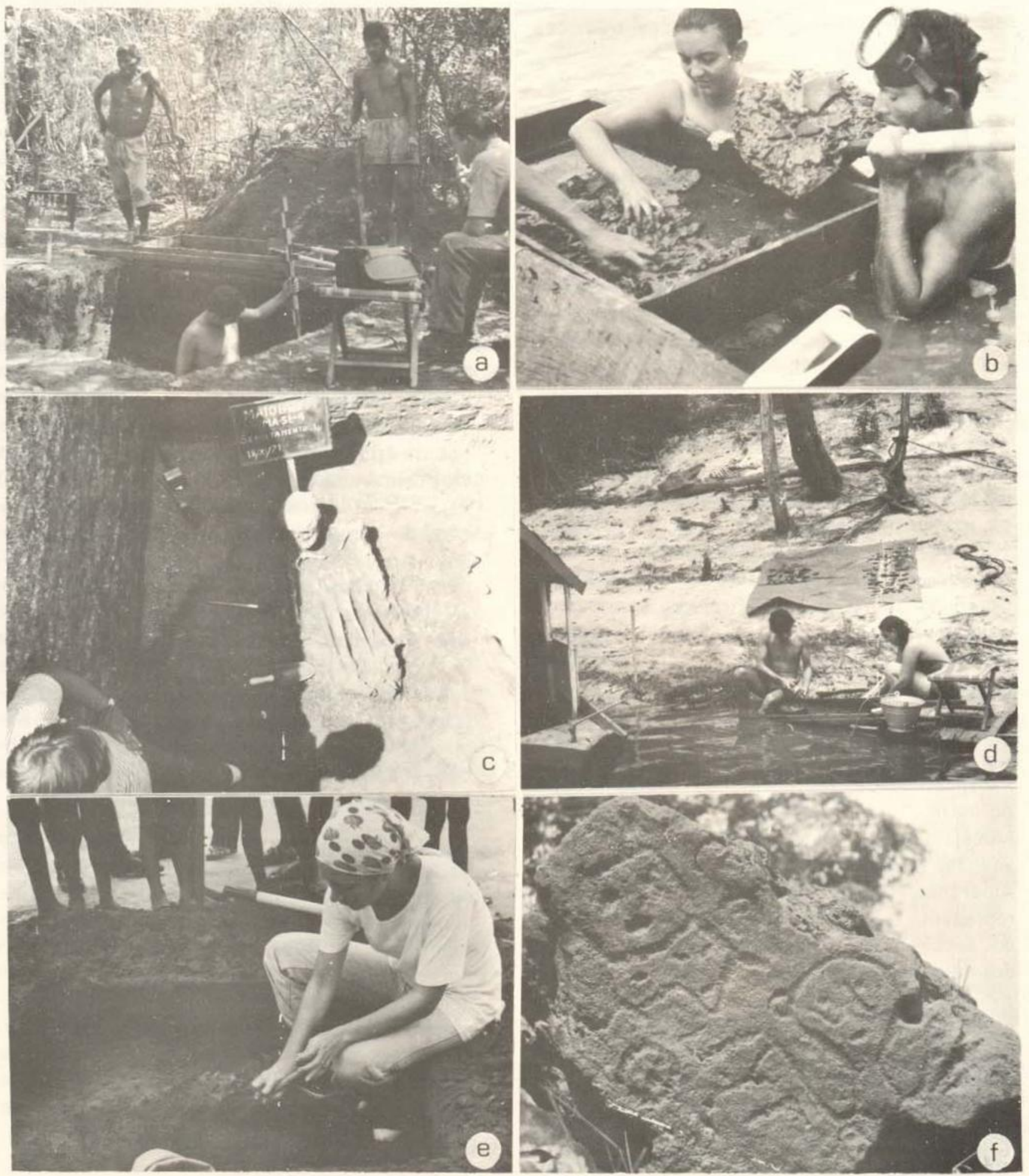

Fig. 6 - Trabalho de campo dos projetos: a - corte-estratigráfico no sítio AM-IT-1: Feitoria, no rio Sanabani, lago de Silves; b - coleta e peneiramento do material retirado do fundo do lago Cajari, no sítio MA-SL-1: Cacaria; c sepultamento fletido entre $1,80-2,00 \mathrm{~m}$ no sambaqui MA.SL-4: Maiobinha, na ilha de São Luis; $\mathbf{d}$ - lavagem de material arqueológico para análise preliminar, médio rio Nagro; e - escavaçăo de uma urna na área urbana da vila de São Sebastião (sítio AM-UR-1), no baixo Uatumã; f. - matacão com petróglifos (sítio AM-IT-31: Caretas), no médio rio Urubu. 
Nova), para fins de delimitação das áreas de dispersão e influência das grandes tradições amazônicas. (Fig. 6a)

Pesquisados 13 sítios-habitaçöes ( 6 na margem norte do lago, 5 no rio Sanabani e 2 na ilha de Silves) e identificadas 3 fases arqueológicas distintas - Silves, Sanabani e Mocajatuba. A fase Silves faz-se representar, principalmente, nos sítios localizados nas falésias da margem norte do lago. Cerâmica muito bem elaborada, com diversos tipos decorados, inclusive pintura policroma. Sepultamento secundário em urnas antropomorfas pintadas $e$ antiguidade por $\mathrm{C}_{14}$ datando de A.D. 200. A fase Sanabani, por outro lado, foi identificada nos sítios das terras firmes de ambas as margens do rio homônimo. Sítios menores que os da fase Silves, com cerâmica apresentando ênfase nas técnicas incisa, ponteada e modela. da, e datação variando de A.D. 940 a A.D. 1060. A terceira fase - Mocajatuba - , foi caracterizada em um único sítio da ilha de Silves. Cerâmica diferente das anteriores e presença de elementos culturais alienígenas (pregos, artefatos de ferro etc.). Datação acusando A.D. 1715.

A fase Silves é tipicamente filiada à subtradição Guarita e a fase Sanabani à tradição Incisa Ponteada, representando ambas grupos de horticultores de floresta tropical. Já a fase Mocajatuba, por conter evidências aculturativas, foi incluída na tradição Neo-brasileira da Amazônia. O sítio dessa fase provavelmente representa o local onde foi construída, em fins do século XVII, uma missão para catequese dos índios do rio Urubu. (Simões, 1973).

\section{6 - Projeto lago Cajari (1971) - Pesquisa} efetuada por Mario F. Simões, Conceição G. Corrêa, Ana Lucia Machado e Renato Sampalo Corrêa, na baixada maranhense, com financia. mento do IPHAN. O projeto visava tentar resolver as controvérsias sobre a origem e antiguidade dos remanescentes culturais encontrados por Raimundo Lopes, em 1919, nas estearias ou palafitas do lago Cajari, no Maranhão. (Fig. 6b)
Localizadas e pesquisadas as estearlas da Cacaria e a do Igarapé do Baiano, ambas no lago Cajari e noticiadas por aquele autor. Selecionada a estação seca para realização dos trabalhos de prospecção subaquática, foram localizados restos dos antigos esteios de sustentação das palafitas, delimitada a área de ocupação da aldeia e coletada no fundo do lago grande quantidade de material (fragmentos de cerâmica, artefatos líticos, restos de esteios, madeira queimada e carvão). Da aná. lise dessas evidências resultou a identificação da fase Cajari, relacionada à cultura das estearlas maranhenses. A aldeia da fase Cajari, a julgar pelo sítio-tipo da Cacaria, abrangia área elíptica irregular de cerca de $8.000 \mathrm{~m}^{2}$, com os esteios de sustentação do tabuado em troncos de "pau d'arco" (Tabebuia sp.) enterrados verticalmente, em média $1,20 \mathrm{~m}$, no fundo do lago; ontre estes ocorriam esteios secundários, de menor diâmetro e geralmente inclinados. Acima do nível máximo das águas estendia-se o tabuado ou piso, sobre o qual, provavelmente, se distribuiam as cabanas. Cerâmica com tipos distintos de tempero e com ênfase no modelado de asas e adornos. Artefatos de cerâmica incluindo grelhas ou assadores circulares, rodelas-de-fuso e vasos miniaturas. Numerosa e variada quantidade de artefatos líti$\cos$ polidos e lascados. Uma única datação por $\mathrm{C}_{14}$ acusou uma antiguidade de A.D. 570.

A presença de grelhas implica na utilizaçăo da mandioca ou outro qualquer tubérculo, raiz ou coco, sob a forma de bolo ou de farinha na alimentação, enquanto as rodelas-de-fuso sugerem fiação de fibras ou algodão para confecção de linhas, redes etc., o que parece evidenciar uma subsistência voltada para a pesca e agricultura. Apesar de contemporânea com algumas fases da ilha de Marajó, não há entre a fase Cajari e as antigas culturas daquela ilha qualquer correlação cultural, como sugerida no passado. (Simões, 1973; Simões et al., 1977).

7 - Projeto São Luís (1971) - Patrocinado pelo Museu Goeldi e realizado pela mesma equipe do projeto anterior, $\left({ }^{8}\right)$ o projeto visava a localizaçấo e pesquisa dos sambaquis litorâneos

(8) - Na parte final do trabalho de campo, quando nes dirigíames para um dos sambaquis, ocorreu o brusco falecimento em pleno campo de Renato Sampaio Corrêa, 
da ilha de São Luís (MA) para fins de comparação cultural e cronológica com os do litoral do Pará (fase Mina) e do Recôncavo Baianc (fase Periperi). (Fig. 6c)

Localizados e pesquisados 8 sambaquis, dos quais apenas dois - Maiobinha e Guaíba - permitiram escavações estratigráficas. Os restantes, como no litoral do Salgado, mostravam-se totalmente destruídos, restando somente fina camada residual de conchas e fragmentos de cerâmica. Com exceção do sambaqui da Maiobinha, os demais apresentavam composição malacológica semelhante aos da fase Mina, isto é predomínio de Anomalocardia brasiliana e Crassostrea sp. O sambaqui da Maiobinha apresentou refugo ocupacional de cerca de $2,0 \mathrm{~m}$ de espessura, composto principalmente por valvas de Chione pectorina em mistura com fragmentos de cerâmica, de líticos, vértebras de peixes, ossos de animais etc. Junto à base continha ainda dois sepultamentos primários diretos: de uma mulher em posição fletida e decúbito dorsal, associado a contas líticas de provável colar; e outro, mais abaixo, de uma criança de colo também associado com minúsculas contas íticas. O sambaqui de Guaíba, por sua vez, fora parcialmente destruído, exibindo um refugo residual de apenas $1,0 \mathrm{~m}$ de profundidade com sinais de perturbação. Ainda que diferentes entre si, as cerâmicas de ambos mostram-se melhor confeccionadas que as dos demais sambaquis locais, inclusive com técnicas decorativas sofisticadas. Duas amostras de carvão do sambaqui da Maiobinha forneceram datações de A.D. 545 e A.D. 705. (Simões, 1973).

Excluídos os dois acima citados, os demais sambaquis pesquisados foram tipologicamente filiados à tradição Mina do litoral paraense e baixo Amazonas.

8 - Projeto Baixo rio Tocantins (1976-1979) Projeto financiado pelo Programa Nacional de Pesquisas Arqueológicas na Bacia Amazônica
(PRONAPABA), $\left({ }^{9}\right)$ em 1976, e realizado por Mario F. Simões, Eneida Ch. Malerbi e Fernanda de Araujo-Costa nos trechos MarabáSanta Terezinha e Tucuruí-Nazaré dos Patos. Porém, tendo em vista a construção da represa de Tucuruí e a futura inundação da área acima da hidrelétrica, mediante acordo com a ELETRONORTE, foi providenciado em 1977 o salvamento arqueológico da área, levado a efeito por Mario F. Simões, Fernanda de Araujo-Costa e Ana Lucia Machado. Em 1978, retornam ao campo as duas últimas para completar os trechos intermediários e, em 1979, Daniel F. Fróis Lopes viajou para Marabá para salvamento de mais 2 sítios ameaçados de destruição por erosão e desmatamento. Além dos objetivos específicos do PRONAPABA (Simões, 1978) e de Salvamento Arqueológico, a pesquisa tinha por finalidade verificar, pela posição geográfica da área, a possibilidade desta ter servido como centro receptor e/ou de passagem de grupos pré-históricos de sudeste, centro e norte do Brasil.

Localizados e pesquisados 40 sítios arqueológicos ao longo do baixo Tocantins e seus afluentes, no trecho Marabá-Nazaré dos Patos, e identificadas até o momento 3 fases arqueológicas distintas - Tauari, Tucuruí e Tauá. A fase Tauari foi identificada nos sítios localizados entre Marabá e Jatobal, apresentanto cerâmica utilitária com ênfase no banho vermelho, corrugado e roletado; artefatos líticos compreendendo lâminas-de-machado, batedores, facas e raras pontas-de-projétil. Evidências de sepultamento secundário em urnas. A fase Tucuruí, reconhecida nos sítios localizados entre a corredeira de Capitariquara e Tucurui, inclusive ao longo da antiga ferrovia Jatobal-Tucurui, apresentou cerâmica melhor manufaturada, com pintura, incisão e modelado. Arteíatos líticos semelhantes ao da fase Tauari e sepultamento primário direto na área do sítio. Já a fase Tauá, caracterizada nos sítios à jusante de Tucuruí mostrou uma cerâmica mui-

(9) - Programa de grande amplitude e participação interinstitucional, em realização mediante convênio entre o. CNPq e a Smithsonian Institution, com a colaboração da SPHAN, INPA e Museu Goeldi. É coordenado por Clifford Evans (até janeiro de 81) e Betty Meggers, pela Smithsonian Institution, e Mário F. Simōes, pelo CNPq/Museu Goeldi, dele participando, além do pessoal da Divisão de Arqueologia do Museu Goeldi, Colso Perota (UFES), Ondemar F. Dias Jr (UFRJ) e Eurico Th. Miller (UCRS), com respectivas equipes. Iniciado em 1976, com previsão para 5 anos, tendo sido já pesquisadas várias áreas do Pará, Amazonas, Acre e Rondônia (Simões, 1977). 
to elaborada, com várics tipos decorativos. totalmente diversa das duas anteriores.

A fase Tauari foi datada em A.D. 1550 , enquanto a Tucuruí em A.D. 1000. Todas três fases pertencem a horticultores de floresta tropical, relacionando-se as duas primeiras a grupos com forte influência na cerâmica com a tracição Tupiguarani. Já a fase Tauá, pelas características da cerâmica, é tipicamente relacionada com a tradição Incisa Ponteada da Amazônia (Simões, s/d).

9 - Projeto Médio rio Negro (1978) - Pesquisa programada e patrocinada pelo PRONAPABA no curso médio do rio Negro, entre as fozes dos rios Cuieiras e Ararirrá, e realizada por Mario F. Simões, Ana Lucia Machado e Ana Lucia Maroja. Além dos objetivos do Programa, buscava ainda o projeto complementar as pesquisas anteriores no baixo cusro do rio. (Fig. 6d).

Pesquisados 20 sítios arqueológicos ao longo da calha do rio e baixo curso de vários de seus afluentes. São todos sítios-habitações localizados em locais elevados e próximo à margem do rio. Ainda que grande parte do material se encontre em processo de análise e classificação, pode-se adiantar que há uma preponderância de sítios com material típico da subtradição Guarita, em especial da fase Apuaú (Simões, 1974). Há ainda ocorrência de material que, pelas formas e decoração exibidas, não se enquadra nas fases e tradições comuns da região, além de pequena incidência de cerâmica neo-brasileira.

Datações para alguns sítios com traços diagnósticos da subtradição Guarita acusaram A.D. 880 e A.D. 990 , enquanto duas outras - A.D. 1220 e A.D. 1325 - procedem de sítios com material inédito (Simões, s/d).

10 - Projeto Baixo Uatumã/Jatapu (1979) Patrocinado pelo PRONAPABA para pesquisas nos cursos inferiores dos rios Uatumã e Jatapu $(\mathrm{AM})$, e realizadas por Mario $\mathrm{F}$. Simões, Conceiçăo G. Corrêa, Ana Lucia Maroja e Lilia G. Nasser. Objetivos adicionais aos do Programa compreendendo tentativa de identificação das áreas de influências das duas grandes tradições ceramistas amazônicas. (Fig. 6e)
Localizados e pesquisados 27 sítios no baixo Uatumã, baixo Maripá, baixo Jatapu, paraná de Urucará e furo de Silves. Com exceção de um único sítio, onde foram escavadas urnas de sepultamento secundário, todos os demais são sítio-habitações. Embora o material esteja em fase de análise preliminar, há grande número de sítios com material tipicamente da tradição Policroma, especialmente da subtradição Guarita, inclusive com urnas antropomorfas policromas. Presença ainda de sítios com material assemelhado ao da fase ou complexo Konduri, da tradição Incisa Ponteada, de distribuição geográfica nos rios Nhamundá e Trombetas. (Simões, $s / d$ ) .

11 - Projeto Médio rio Urubu (1980) - Projeto financiado pelo PIN-Trópico Úmido e realizado por Mario F. Simões, Ana Lucia Maroja e Daniel F. Frois Lopes no curso médio do rio Urubu (AM), tendo por objetivo complementar as pesquisas anteriores no lago de Silves e baixo rio Negro. (Fig. 6f)

Localizados e pesquisados 23 sítios ao longo do curso médio do rio, da foz do rio Anebá até o lago da Glória. Pela recência do trabalho de campo (novembro-dezembro) e o material estar ainda sendo lavado e etiquetado, somente é possível adiantar que maior parte dos sítios apresenta evidências de material assemelhado ao da fase Silves, do lago de Silves.

\section{ACERVO AROUEOLOGICO}

Até 1954 o acervo arqueológico do Museu Goeldi não ultrapassava 700 peças e fragmentos, dentre as quais a coleção de Lima Guedes (Maracá) e a de Goeldi (Cunani). Em 1959, adquire o $\mathrm{CNPq}$ por compra a valiosa Coleção Frederico Barata, organizada por esse estudioso da Cultura Santarém, depositando-a no Museu Goeldi para fins de conservação e exposição.

Atualmente, conta o acervo com 2.054 peças tombadas, constando de exemplares completos, incompletos e restaurados, além de, aproximadamente, 800.000 fragmentos de cerâmica, de artefatos líticos etc., procedentes das escavações estratigráficas e coleções de superfície dos inúmeros sítios pesquisados nos últimos anos. Das peças completas e restauradas. 
destacam-se, além daquelas já citadas acima, as coleções Nimuendajú, Townsend e Barata (Santarém e Oriximiná), Evans \& Meggers (Marajó e Amapá), Frikel (Baixo Amazonas, rio Cururu e Tumucumaque), Corrêa, Figueiredo \& Simões (Marajó), J.C. Cardoso (Marajó). Simões (Salgado, Negro e Uatumã) e INPA (Silves e Solimões).

\section{PUBLICAÇÕES}

Além dos resultados das pesquisas realizadas e já citados no texto, outros trabalhos vêm sendo publicados pelo Museu Goeldi, como a cerâmica arqueológica do rio Itacaiúnas (Figueiredo, 1965), estatuetas de cerâmica na Cultura Santarém (Corrêa, 1965), cerâmica arqueológica do rio Fresco (Simões et al., 1973), reconstituição da pré-história da Amazônia (Meggers \& Evans, 1973), pontas-de-projétil no Tapajós (Simões, 1976) e arqueologia dos rios Nhamundá/Trombetas (Hilbert \& Hilbert, 1980). Somam-se, ainda, alguns trabalhos sobre metodologia e informação arqueológicas, como o pequeno manual para prospecção arqueológica (Evans \& Meggers, 1965), os resultados preliminares do Programa Nacional de Pesquisas Arqueológicas (Simões, Ed., 1967, 1969a, 1969b, 1971 e 1974), uma sinopse sobre a Arqueologia do Brasil (Brochado et al., 1969), o indice das fases arqueológicas (Simões, 1972) e, mais recentemente, as áreas da Amazônia Legal Brasileira para fins de cadastro e pesquisa de sitios arqueológicos (Simões \& Araujo-Costa, 1978)

\section{CONSIDERAC̣ÕES FINAIS}

No período de 1955 ao presente, não obstante o reduzido pessoal de pesquisa e apoio, foram realizadas pela Divisão de Arqueologia as seguintes atividades: co-direção científica de 2 programas nacionais e interinstitucionais (PRONAPA e PRONAPABA); programados e executados 14 projetos de pesquisa; localizados e pesquisados 308 sítios arqueológicos; identificadas mais de 40 fases, uma tradição (Mina) e uma subtradição (Guarita); obtidas cerca de 70 datações por $\mathrm{C}_{14}$ e Termoluminescência $€$ publicados 38 trabalhos, entre artigos e monografias.
No campo do ensino e treinamento de pessoal foram ministrados 2 cursos de Arqueolo. gia em nível de pós-graduação, concedidos 6 estágios especiais e 18 regulares, proferidas váriłs palestras e conferências e montadas 4 exposições.

No tocante às coleções arqueológicas ou acervo, foram estas totalmente revisadas quanto ao seu tombamento, restauradas aquelas em mau estado e iniciado o fichamento descritivo-tipológico de cada espécime. Acrescidos mais 1355 espécimes tombados, além de cerca de 800.000 fragmentos diversos das coleções estratigráficas.

\section{SUMMARY}

The development of archeological research in the Museu Paraense Emilio Goeldi is due in large part to the Conselho Nacional de Desenvolvimento Cientifics e Tecnológico (CNPq) which, beginning in 1954, reorganized, reequiped, and revitalized the former Section cf Amazonian Archeology. The history of Archeolog\% in the Museu Goeldi is traced from its founding to the present day. At the time of the entry of the CNPq into the administration of the Museum, the old Section of Amazonian Archeology had been practically inactive since the beginning of the 20th century. Today, the Division of Archeology includes 5 researchers and technicians and curates a collection of artefacts which numbers over 2000 pieces. The principle research projects which have been carried out or are still in progress are discussed, as are collateral activities in the fields of education and the conservation of archeological sites.

\section{REFERENCIAS BIBLIOGRAFICAS}

BROCHADO, J. Proenza et alii.

1969 - Arqueologia Brasileira em 1968. Um rela. tório sobre o Programa Nacional de Pesquisas Arqueológicas. Publ. Avulsas Mus $\mathrm{Pa}$. Emilio Goeldi, Belém, 12. 33 p. il.

CORRÊA, Conceição G.

1965 - Estatuetas de cerâmica na Cultura Santarém. Publ. Avulsas Mus. Pa. Emílio Goeldi, Belém, 4. $90 \mathrm{p}$. il.

CORREA, Conceição G. \& SIMŌES, Mário F.

1971 - Pesquisas arqueológicas na região do Sal gado (Pará). A fase Areão do litoral de $\mathrm{Ma}$. rapanim. B. Mus. Pa. Emilio Goeldi, n. ser. Antrop., Belém, 48,30 p. il.

EVANS, Clifford \& MEGGERS, Betty J.

1965 - Guia para prospecçẵo arqueológica no Brasil. Belém, Museu Paraense Emílio Goeldi, VIII +57 p. il. (Série Guias, 2). 
FERREIRA PENNA, Domingos S.

1876 - Breve notícia sobre os sambaquis do Pará. Arch. Mus. Nac., do Ric de Janeiro, 1: 85-99.

1877a - Apontamentos sobre os ceramios do Pará. Arch. Mus. Nac., Rio de Janeiro, 2: 47-67.

1877b- Urnas de Maracá. Arch. Mus. Nac., Rıo de Janeiro, 2: 69-71.

FIGUEIREDO, Napoleão

1965 - A cerâmica arqueológica do rio Itacaiúnas. B. Mus. Pa. Emilio Goeldi, n. ser. Antrop., Belém, 27. $17 \mathrm{p}$. il.

FIGUEIREDO, Napoleão \& SIMOES, Mário F.

1963 - Contribuição à arqueologia da fase Marajoara. Rev. Mus. Paul., São Paulo, 14: 45565. il.

GOELDI, Emilio

1900 - Excavações archeologicas em 1895. 1." parte: As cavernas funerarias artificiaes dos indios extinctos no rio Cunany (Goanany) e sua ceramica. Mem. Mus. Pa. Hist. Nat. Ethnogr., Belém, 1. 43 p. il.

GUEDES, Aureliano Lima

1897 - Relatório sobre uma missão ethnographica e archeologica aos rios Maracá e Anauerapucú. B. Mus. Pa. Hist. Nat, Ethnogr. Belém, 2: 42-64.

HILBERT, Peter P.

1952 - Contribuição a arqueologia da liha de Marajó. Os "tesos" marajoaras do alto $\mathrm{Ca}$ mutins e a atual situação da llha do Pacoval, no Arari. Inst. Antrop. Etnol. Pará, Belém, 5. 32 p. il.

1955a- Tripods in the lower Amazon. In: CONGRES. INTERN. AMERICAN., 31. São Paulo, Anais... 2: 42-64. il.

1955b- A cerâmica arqueológica da região de Oriximiná. Inst. Antrop. Etnol. Pará, Belém, 9. 76 p. il.

1957 - Contribuição à arqueologia do Amapá. Fase Aristé. B. Mus. Pa. Emílio Goeldi, n. ser. Antrop., Belém, 1. 37 p. il.

1958 - Urnas funerárias do rio Cururu, Alto Tapajós. B. Mus. Pa. Emilio Goeldi, n. ser Antrop., Belém, 6. 13 p. il.

1959a- Achados arqueológicos num sambaqui do Baixo Amazonas. Inst. Antrop. Etnol. Pará, Belém, 10. 20 p. il.

$1959 \mathrm{~b}$ - Preliminary results of archeological investigations in the vicinity of the mouth of the Rio Negro, Amazonas. In: CONGRES. INTERN. AMERICAN., 33. San José. Actas... 2: 370-77. il.

$1962 a$ - New stratigraphic evidence of culture change on the middle Amazon (Solimōes). In: INTER. AMERIKANISTNKONGRESSES, 34. Wien. Akten... p. 471-76. II. 1962b- Preliminary results of archaeological research on the Japurá River. Middle Ama. zon. In: INTER. AMERIKANISTNKONGRESSES, 34. Wien. Akten... p. 465-70. il.

1968 - Archaelogische Untersuchungen am mittleren Amazonas. Beitrage Zur Vorgeschichle des Sudamerikanischen Tieeflandes. Marburger Stud. Zur Volkerk., Berlin, 1. $281 \mathrm{p}$ il.

HILBERT, Peter Paul \& HILBERT, Klaus

1980 - Resultados preliminares da pesquisa arqueológica nos rios Nhamundá e Trombetas, Baixo Amazonas. B. Mus. Pa. Emilio Goeldi, n. ser. Antrop., Belém, 75. 11 p. il.

KATZER, Friedrich

1903 - Grundzüge der Geologie des unteren Amazonasgebietes (des Staates Pará in Brazilien). Leipzig, M. Weg. 296 p. il.

KRAATZ-KOSCHLAU, K.A. Von \& HUBER, J.

1900 - Zwischen Ocean und Guamá. Beitrag zur Kenntniss des Staates Pará. Mem. Mus

Pa. Hist. Nat. Ethnogr., Belém, 2. 34 p. Hl.

MEGGERS, Betty J. \& EVANS, Clifford

1957 - Archeological investigations at the mouth of the Amazon. Bur. Amer. Ethnol. Bull., 167. 664 p. il.

1973 - A reconstituição da pré-história Amazônica. Algumas consideraçōes teóricas. In: SIMOES, M.F. - O Museu Goeldi no Ano do Sesquicentenário. Publ. Avulsas Mus. Pa Emilio Goeldi, Belém, 20 p. 51-69. II,

NIMUENDAJÚ, Curt

1949 - Os Tapajós. B. Mus. Pa. Emílio Goeldi, Belém, 10: 93-106.

SIMOES, Mário F.

1967a - Resultados preliminares de uma prospecção arqueológica na região dos rios Goiapi e Camará (Illha de Marajó). In: SIMPÓSIO SOBRE A BIOTA AMAZONICA. Rio de Janeiro. Atas. v. 2 Antropologia. p. 207-24 4.

1967b- Consideraçōes preliminares sobre a arqueologia do alto Xingu (Mato Grosso). In: PROGRAMA NACIONAL DE PESQUISAS ARQUEOLOGICAS. Resultados preliminares do primeiro ano. 1965-66. Publ. Avulsas Mus Pa. Emílio Goeldi, Belém, 6: 129-52. il.

1969 - The Castanheira Site: New evidence on the antiquity and history of the Ananatuba Phase (Marajó Island, Brazil). Amer. Antiq., Salt Lake City, 34 (4): 402-10. il.

1971 - O Museu Goeldi e a Arqueologia da Bacia Amazônica. In: ROCQUE, C. Antologia da Cultura Amazônica. São Paulo, Ediçōes Cu!turais, p. 172-80., il. (Antropologia-Folclores, 6).

1972 - Indice das fases arqueológicas brasileiras. 1950-1971. Publ. Avulsas Mus. Pa. Emilio Goeldi, Belém, 18. 75 p. il. 
1973 - A pesquisa arqueológica na Amazônia Legal Brasileira. In: Dédalo, São Paulo, 17/18; 11-23. il.

1974 - Contribuição à arqueologia dos arredores do baixo rio Negro. In: PROGRAMA NACIONAL DE PESQUISAS ARQUEOLOGICAS. Resultados preliminares do quinto ano. 1969-70. Publ. Avulsas Mus. Pa. Emilio Goeldi, Belém, 26: 165-88. il.

1976 - Nota sobre duas pontas-de-projétil da bacia do Tapajós (Pará). B. Mus. Pa. Emílio Goeldi, n. ser. Antrop., Belém, 62. 14 p. il.

1977 - Programa Nacional de Pesquisas Arqueológicas na Bacia Amazônica. Acta Amazonica, Manaus, 7 (3): 297-300. il.

1981 - Coletores-pescadores ceramistas do litoral do Salgado. Nota preliminar. B. Mus. Pa. Emilio Goeldi, n. ser. Antrop., Belém, 78. 26 p. il.

sd - O Programa Nacional de Pesquisas Arqueológicas na Bacia Amazônica. Áreas pesqui sadas nos três primeiros anos (1977-79). Fundação de Desenvolvimento da Pesquisa de Minas Gerais, Belo Horizonte. (no prelo).

SIMŌES, Mário F. \& ARAUJO-COSTA, Fernanda

\footnotetext{
1978 - Áreas da Amazônia Legal Brasileira para pesquisa e cadastro de sítios arqueológicos. Publ. Avulsas Mus. Pa. Emílio Goe:di, Belém, 30. 160 p. il.
}

SIMŌES, Mário F.; CORREA. Conceição G.; MACHADO, Ana Lucia

1973 - Achados arqueológicos no baixo rio Fresco (Pará). In: Simões, M.F. - O Museu Goeldi no Ano do Sesquicentenário. Publ. Avulsas Mus. Pa. Emilio Goeldi, Belém, 20. p. 11342. il.

1977 - Pesquisas arqueológicas nas estearias do lago Cajari, Maranhāo. In: RESUMOS da 29." Reunião Anual da SBPC, São Paulo, p. 162-3.

SIMŌES, Mário F. (Editor)

1967 - Programa Nacional de Pesquisas Arqueoló gicas. Resultados preliminares do primeiro ano. 1965-66. Publ. Avulsas Mus. Pa. Emilio Goeldi, Belém, 6. 158 p. il.

1969a - Programa Nacional de Pesquisas Arqueológicas. Resultados preliminares do segundo ano. 1966-67. Publ. Avulsas Mus. Pa. Emilio Goeldi, Belém, 10. 152 p. il.

1969b- Programa Nacional de Pesquisas Arqueológicas. Resultados preliminares do terceiro ano. 1967-68. Publ. Avulsas Mus. Pa. Emílio Goeldi, Belém.

1971 - Programa Nacional de Pesquisas Arqueoló gicas. Resultados preliminares do quarto ano. 1968-69. Publ. Avulsas Mus. Pa. Emílio Goeldi, Belém, 15. 190 p. il.

1974 - Programa Nacional de Pesquisas Arqueológicas. Resultados preliminares do quinto ano. 1969-70. Publ. Avulsas Mus. Pa. Emilio Goeldi, Belém, 26. 200 p. il. 